\title{
Short-term effects of tagging on activity and movement patterns of Eurasian beavers (Castor fiber)
}

\author{
P. M. Graf ${ }^{1,2}$ • J. Hochreiter ${ }^{1}$ - K. Hackländer ${ }^{1}$ • R. P. Wilson ${ }^{3} \cdot$ F. Rosell $^{2}$
}

Received: 6 May 2016 /Revised: 23 August 2016 / Accepted: 13 September 2016/Published online: 28 September 2016

(C) The Author(s) 2016. This article is published with open access at Springerlink.com

\begin{abstract}
Bio-logging is becoming increasingly popular amongst wildlife researchers, providing a remote way of monitoring free-ranging animals in their natural habitats. However, capturing and tagging can be stressful and may alter animal behaviour. In this study, we investigated whether tagging altered activity and movement patterns of Eurasian beavers (Castor fiber) during the first week after release, predicting that beavers would be less active, travel shorter distances and stay closer to the lodge in the first nights after the tagging event. We captured 29 dominant free-ranging beavers (12 females, 17 males) in Telemark county, Norway, and tagged them with GPS units ( $n=23 ; 12$ males, 11 females) and triaxial acceleration data loggers $(n=14 ; 9$ males, 5 females). Accelerometer data was used to investigate activity levels (using mean overall dynamic body acceleration ODBA and principal activity periods), while GPS data was used to determine movement patterns (using distance moved and lodge displacement rate). Tagging effects were apparent only in activity levels of beavers, where we found lower mean ODBA
\end{abstract}

Electronic supplementary material The online version of this article (doi:10.1007/s10344-016-1051-8) contains supplementary material, which is available to authorized users.

P. M. Graf

patricia.m.graf@hit.no

1 Institute of Wildlife Biology and Game Management, University of Natural Resources and Life Sciences, Vienna, Gregor-Mendel-Str. 33, 1180 Vienna, Austria

2 Faculty of Arts and Sciences, Department of Environmental and Health Studies, University College of Southeast Norway, 3800 Bø i Telemark, Norway

3 Biological Sciences, Institute of Environmental Sustainability, Swansea University, Swansea SA2 8PP, UK values after release although the small effect size (Cohen's $d=$ 0.17 ) indicates only a minimal difference in activity. Neither principal activity periods nor distances moved or lodge displacement rate changed within the first week after release, which indicates that beavers were active and post-release space use within the territory was not affected by the tagging event in this respect.

Keywords Accelerometer · Activity · Castor fiber - GPS . Movement $\cdot$ Tagging effects

\section{Introduction}

The tagging of wild animals with miniaturized electronic devices has proved pivotal to many wildlife studies and has now become a commonplace within the field of animal ecology (Cagnacci et al. 2010; Rutz and Hays 2009). In particular, bio-logging technology, which specifically deals with logging sensor-derived parameters from animal-attached tags, now includes systems such as implants, anchors, glue-on tags and collar or harness-mounted units (i.e. Cooke et al. 2011; Kays et al. 2015). These tags can be equipped with a suite of sensors related to animal state, such as heart beat frequency and/or body temperature (Butler et al. 2004; Evans et al. 2016; Friebe et al. 2014), but may also document movement patterns (Rhodes et al. 2005; Zimmermann et al. 2007), general activity, behaviour and proxies for energy expenditure (Shepard et al. 2008; Wilson et al. 2006). Such tags can be used under challenging environmental conditions, including aquatic (Gleiss et al. 2011; Thorrold et al. 2014) and terrestrial habitats (Steyaert et al. 2014; Williams et al. 2014), as well as on species that spend a considerable amount of their time in air (Nathan et al. 2012; Spiegel et al. 2015). The general premise is that such tags allow free-living animals to be studied with 
only minor disturbance (Boyd et al. 2004; Ropert-Coudert and Wilson 2005) and minimal observer effects (Cagnacci et al. 2010) while delivering insights into animal behaviour and ecology (Shillinger et al. 2012; Weimerskirch 2007) with potential implications for conservation and management actions (Schofield et al. 2007; Wilson et al. 2015).

Increased focus on miniaturization has led to reduced size and weight of bio-loggers, extending the application range to even smaller animals (i.e. Kissling et al. 2014; O’Mara et al. 2014) and reduced perceived impact on tagged animals in general (Golabek et al. 2008; Ropert-Coudert et al. 2009). Yet, the capture and tagging procedure can be stressful for the animal (Fletcher and Boonstra 2006; Lapointe et al. 2015) and trigger physical and psychological effects, which can alter the animals' behaviour (Saraux et al. 2011; Wilson 2011). Until recently, many researchers have considered such effects to be negligible (Wilson and McMahon 2006) with, for example, a review on radio transmitter studies by Godfrey and Bryant (2003) reporting that, of 836 published papers, $83.3 \%$ ignored the impact of marking with tracking devices on their study species. Fortunately, since the early 2000s, awareness of capture and tagging-related effects on animals has grown with researchers using various approaches to tackle potential problems (McMahon et al. 2011; Vandenabeele et al. 2015; White et al. 2013). While some studies found no evidence for such effects (McMahon et al. 2008; Ropert-Coudert et al. 2009), others showed tagging-related impacts ranging from physiological effects, such as changes in cortisol levels (Cattet et al. 2014) or capture myopathy (Höfle et al. 2004; Ponjoan et al. 2008), to behavioural effects including changes in movement and space use (Morellet et al. 2009; Rachlow et al. 2014) or generally reduced activity (Broell et al. 2016; Dennis and Shah 2012). Tagging effects may accumulate over time and can have detrimental influence on life history parameters such as reproductive success or survival rate (Barron et al. 2010; Blanchet et al. 2014; Casas et al. 2015), or may only be shorttermed and diminish over time (Dennis and Shah 2012; Morellet et al. 2009).

Awareness of tagging-induced effects is not only important for the sake of animal welfare but should also be considered to prevent biased research results (Dechen Quinn et al. 2012; Ropert-Coudert and Wilson 2005). In particular, determination of effects which occur immediately after releasing the animal is important for researchers working with relatively short-term datasets. Such tagging effects can be assessed via direct observations of tagged individuals (Gendron et al. 2014) and/or a control group (Authier et al. 2013; RopertCoudert et al. 2007), by measuring physiological parameters such as blood sampling (Montané et al. 2002; St. Aubin et al. 2013) or by using the logged data itself (Broell et al. 2016; Rachlow et al. 2014). A particular value of bio-logged data for examining tagging effects is that it is effectively seamless and has high temporal resolution.
In this study, we investigated the short-term effects of capture, handling and tagging (hereafter "tagging") on a semiaquatic, nocturnal rodent, the Eurasian beaver (Castor fiber). Both beaver species (C. fiber and the North American beaver Castor canadensis) are socially monogamous and live in colonies consisting of a dominant pair and their non-dominant offspring including kits, yearlings and individuals of 2 years or older (Campbell et al. 2005; Novak 1987). They are highly territorial and deposit scent mounds at territory boarders in order to advertise occupation (Rosell et al. 1998; Schulte 1998; Sun and Müller-Schwarze 1999). Beavers are herbivores with a preference for softwood such as poplars (Populus sp.) and willows (Salix sp.), terrestrial herbs and forbs, ferns and aquatic vegetation (Bergman and Bump 2015; Haarberg and Rosell 2006; Wilsson 1971). As centralplace foragers, they typically return to the shoreline to consume their food (Haarberg and Rosell 2006; Jenkins 1980). The beaver's principal activity period (time the animals start/ end their activity) is approximately from 07:00 pm to 07:00 am (Sharpe and Rosell 2003). This nocturnal activity means that beavers cannot easily be observed and makes them ideal candidates for logging technology.

By examining acceleration and GPS data, we aimed to determine acute tagging effects on Eurasian beaver activity and movement patterns during the first week after the tagging event. Two studies have reported such effects for Eurasian beavers who were implanted with intraperitoneal radio transmitters and found that the animals spent more time inside their lodges within the first few days after release (Ranheim et al. 2004; Sharpe and Rosell 2003, respectively). However, postrelease differences in movement and/or activity patterns were not investigated in detail in these studies, nor did the authors report the significance of their findings. We hypothesized that beavers would alter their activity and movement patterns in response to the tagging procedure. We predicted that beavers show reduced activity both in terms of body movement-based activity level (measured as mean overall dynamic body acceleration, ODBA) and principal activity period, travel shorter distances and stay closer to the lodge in the first nights after tagging. Finally, we predicted that such effects would decrease during the observed period, due to habituation and recovery.

\section{Methods}

\section{Study area and animals}

The data for the study was collected between 2009 and 2014 in Telemark County, southeastern Norway $\left(59^{\circ} 23^{\prime} \mathrm{N}, 09^{\circ} 09^{\prime}\right.$ E). The study site consists of the rivers Gvarv, Straumen and Sauar, all three rivers empty into Lake Norsjø. The rivers flow through a landscape dominated by semi-agricultural and riparian woodland structures; the latter are formed by species such 
as grey alder (Alnus incana), willow (Salix spp.), bird cherry (Prunus padus) and birch (Betula spp.) (Haarberg and Rosell 2006). Eurasian beavers have inhabited the area since the 1920s (Olstad 1937) and the population has been at carrying capacity for the last 10 years (Campbell et al. 2005; Steyaert et al. 2015). Beavers in the study area are monitored every year between March and November as part of a long-term capture-mark-recapture study (since 1998) for individual identification (micro-chip and ear-tags) and data acquisition (i.e. Campbell et al. 2013; Cross et al. 2014; Tinnesand et al. 2013). Since 1999, beavers have also been tagged with tracking devices such as VHF transmitters (Herr and Rosell 2004; Ranheim et al. 2004), GPS systems (Steyaert et al. 2015) and tri-axial accelerometers (Graf et al. 2015). Consequently, information on age, sex, social status (dominant, subordinate; see Campbell et al. 2012 for details), territory sizes, group sizes, reproduction and morphometric parameters (e.g. weight, body size, tail length and thickness) was available for beavers in the study area (Campbell et al. 2012, 2013).

\section{Tagging procedure}

Dominant Eurasian beavers were captured during the night (between 7:00 pm and 7:00 am) with a landing net from a boat (Rosell and Hovde 2001). For handling, the animals were transferred into a cloth bag, thereby dispensing with the need for anaesthesia (Fig. 1). We attached tags consisting of a VHFtransmitter $(18 \times 35 \mathrm{~mm}, 10 \mathrm{~g}$; Reptile glue-on series R1910; Advanced Telemetry Systems, Isanti, MN, USA) in combination with an archival tri-axial accelerometer $(15 \times 90 \mathrm{~mm}$, $62 \mathrm{~g}$; JUV Elektronik, Schleswig-Hollstein, GER), or a rechargeable, archival $\mu \mathrm{GPS}$ unit $(50 \times 70 \mathrm{~mm}, 24 \mathrm{~g}$; model G1G 134A; Sirtrack, Havelock North, NZ), or both units (Fig. 1). The units were connected with wire, integrated in $4.5 \mathrm{~mm}$ half-mesh net covering (Mørenot Fishery AS, Møre og Romsdal, NO) and fixed on the lower back, exactly $15 \mathrm{~cm}$ above the scaly tail along the spine using two-component epoxy resin (Fig. 1). The complete attachment, including all units, had a size of $130 \times 90 \mathrm{~mm}$ and weighted approx. $250 \mathrm{~g}$, which accounts for $1.3 \%$ of the body weight of the lightest beaver $(19 \mathrm{~kg})$ used in the study. Additionally, we took measurements (body length, tail length and width) and samples (hair, castoreum and anal gland secretion) from the captured animals, resulting in an average handling time of $44 \pm 25 \mathrm{~min}$. Beavers were then released at the trapping site within in their own territory. GPS systems were programmed to take a position every $15 \mathrm{~min}$ from 7:00 pm to 7:00 am to cover the beavers' principle active period (Sharpe and Rosell 2003). Acceleration data (22 bit resolution) was recorded $24 \mathrm{~h}$ a day at a frequency of $8 \mathrm{~Hz}$. After 2-3 weeks, beavers were located and re-captured via VHF-telemetry and the tags were cut out of the fur with a scalpel (Fig. 1). This procedure only

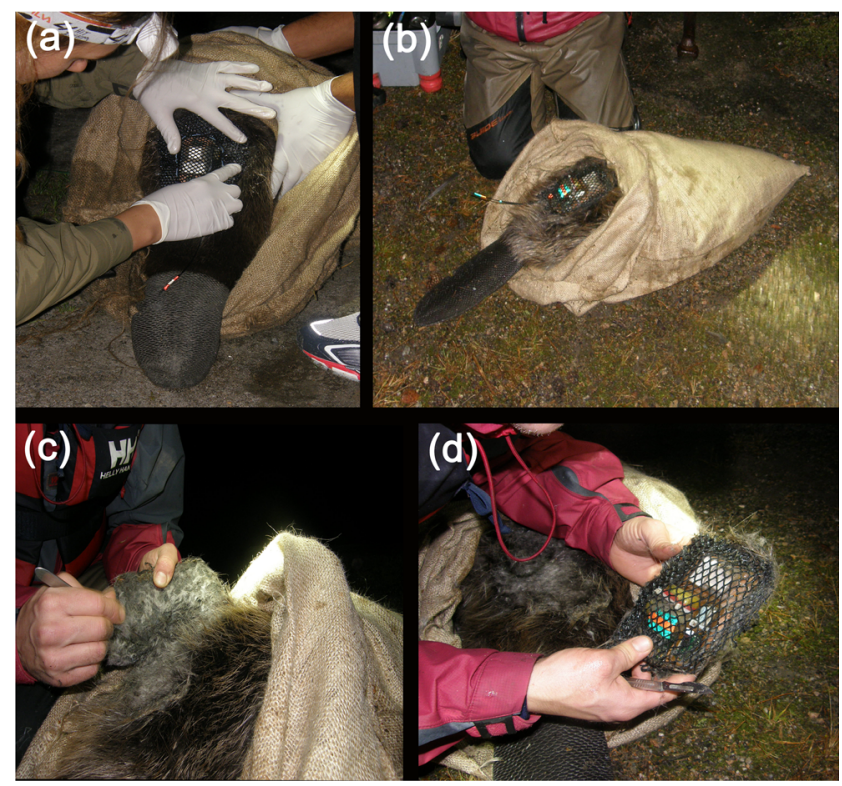

Fig. 1 Tagging procedure and retrieval of tags for Eurasian beavers (C. fiber) in southeastern Norway (2009-2014). Beavers were handled and tagged in cloth bags without the use of anaesthesia. a A GPS unit is glued onto the fur of the lower back ( $15 \mathrm{~cm}$ on top of the scaly tail) using two-component epoxy resin. b By using VHF-telemetry, a beaver tagged both with an accelerometer and a GPS unit has been recaptured. $\mathbf{c}$ The tag is cut out of the guard hair with a scalpel, leaving the under-fur intact. d The tag is retrieved

affected the guard hairs, with the under-fur remaining unaffected (Graf et al. 2015).

\section{Ethical statement}

The study, including all handling and tagging procedures (for details see above), was approved by the Norwegian Experimental Animal Board (FOTS id 742, 2170, 2579, 4387,6282 ) and the Norwegian Directorate for Nature Management (archive code 444.5, 446.15/3), which also granted permission to conduct fieldwork in our study area. The patch of clipped guard hair grew back within 3 to 4 months.

\section{Data analysis}

All data analyses were performed with $\mathrm{R}$ version 3.0.3 ( $\mathrm{R}$ Development Core Team 2013). Accelerometer and GPS data were analysed separately, as we only had combined accelerometer and GPS data for five individuals (Table 1). We used the xts package version 0.9-7 (Ryan and Ulrich 2014) for the accelerometer data and the adehabitatLT package (Calenge 2006) for the GPS data. The accelerometer dataset was cut to time periods between 7:00 pm and 7:00 am (to coincide with previously reported principal activity period for beavers) and shortened to seven nights per individual for standardization. Accelerometer data was used to derive two activity response variables: 'mean overall dynamic body acceleration' 
Table 1 Meta-data of 29 dominant Eurasian beavers (C. fiber) and tagging devices used in this study in Telemark, southeastern Norway (2009-2014)

\begin{tabular}{|c|c|c|c|c|c|c|c|c|}
\hline Beaver & $\mathrm{Tag}^{\mathrm{a}}$ & Territory & $\mathrm{Sex}^{\mathrm{c}}$ & $\mathrm{N}_{\text {night }}{ }^{\mathrm{d}}$ & Season $^{\mathrm{e}}$ & Year $^{f}$ & $\mathrm{~N}_{\text {pos }}{ }^{\mathrm{g}}$ & $\mathrm{N}_{\text {capt }} \mathrm{h}^{\mathrm{s}}$ \\
\hline Chris & $\mathrm{ACC}$ & $\mathrm{L} 5 \mathrm{~b}$ & M & 6 & $\mathrm{~S}$ (Apr) & 2009 & ACC only & 22 \\
\hline Demi & $\mathrm{ACC}$ & $\mathrm{E}$ & $\mathrm{F}$ & 8 & $\mathrm{~A}(\mathrm{Oct})$ & 2009 & ACC only & 2 \\
\hline Easy & $\mathrm{ACC}$ & L5a & M & 7 & $\mathrm{~S}$ (Apr) & 2009 & ACC only & 19 \\
\hline Frode & $\mathrm{ACC}$ & $\mathrm{L} 2 \mathrm{~b}$ & M & 7 & S (May) & 2009 & ACC only & 10 \\
\hline Jan-Marc & $\mathrm{ACC}$ & $\mathrm{P} 0$ & M & 17 & $\mathrm{~A}(\mathrm{Oct})$ & 2011 & ACC only & 5 \\
\hline Kathrin & $\mathrm{ACC}$ & $\mathrm{H}$ & $\mathrm{F}$ & 13 & A (Sept) & 2011 & ACC only & 2 \\
\hline Klumpen & $\mathrm{ACC}$ & GM & M & 8 & $\mathrm{~A}(\mathrm{Oct})$ & 2009 & ACC only & 6 \\
\hline Lasse & $\mathrm{ACC}$ & L2 & M & 7 & S (May) & 2009 & ACC only & 6 \\
\hline Oddi & $\mathrm{ACC}$ & $\mathrm{H}$ & M & 7 & $\mathrm{~A}(\mathrm{Oct})$ & 2009 & ACC only & 4 \\
\hline Apple & GPS & $\mathrm{P} 2 \mathrm{a}$ & $\mathrm{F}$ & 17 & $\mathrm{~A}(\mathrm{Oct})$ & 2013 & 147 & 1 \\
\hline Åse & GPS & P5 & $\mathrm{F}$ & 11 & S (Apr) & 2014 & 134 & 1 \\
\hline Christina & GPS & P3a & $\mathrm{F}$ & 19 & A (Aug) & 2010 & 105 & 3 \\
\hline $\begin{array}{l}\text { Hanne- } \\
\text { Synnove }\end{array}$ & GPS & $\mathrm{P} 0$ & $\mathrm{~F}$ & 11 & A (Aug) & 2010 & 96 & 5 \\
\hline Hazel & GPS & G & $\mathrm{F}$ & 23 & $\mathrm{~S}$ (Apr) & 2010 & 122 & 5 \\
\hline Horst & GPS & P4 & M & 7 & $\mathrm{~A}(\mathrm{Oct})$ & 2010 & 107 & 2 \\
\hline Jan-Marc & GPS & $\mathrm{P} 0$ & M & 17 & A (Aug) & 2014 & 109 & 7 \\
\hline Jodie & GPS & N1 & $\mathrm{F}$ & 12 & $\mathrm{~S}$ (Apr) & 2012 & 122 & 12 \\
\hline Kjartan & GPS & LP & M & 9 & A (Aug) & 2010 & 105 & 2 \\
\hline Klumpen & GPS & GM & M & 12 & $\mathrm{~S}$ (Apr) & 2014 & 126 & 8 \\
\hline Lasse & GPS & $\mathrm{L} 2$ & M & 10 & S (May) & 2011 & 121 & 6 \\
\hline Loran & GPS & L4a & M & 11 & A (Sept) & 2009 & 135 & 15 \\
\hline Malena & GPS & L4a & $\mathrm{F}$ & 9 & S (May) & 2014 & 108 & 2 \\
\hline Manuel & GPS & $\mathrm{P} 1$ & M & 9 & A (Sept) & 2013 & 121 & 1 \\
\hline Moritz & GPS & B2 & M & 7 & A (Aug) & 2010 & 99 & 3 \\
\hline Moses & GPS & $\mathrm{P} 2 \mathrm{~b}$ & M & 15 & A (Aug) & 2010 & 77 & 7 \\
\hline Paddy & GPS & GL & M & 12 & $\mathrm{~S}$ (Apr) & 2012 & 142 & 3 \\
\hline Thomas & GPS & P4 & M & 9 & $\mathrm{~S}$ (Apr) & 2014 & 128 & 1 \\
\hline Andreas & GPS+ACC & B1 & M & $8(\mathrm{G}), 19(\mathrm{~A})$ & $\mathrm{S}$ (Apr) & 2010 & 123 & 8 \\
\hline Erlend & GPS+ACC & $\mathrm{P} 3 \mathrm{~b}$ & $\mathrm{M}$ & $13(\mathrm{G}), 15(\mathrm{~A})$ & $\mathrm{S}$ (Apr) & 2010 & 141 & 6 \\
\hline Ida & GPS+ACC & LP & $\mathrm{F}$ & $14(\mathrm{G}), 19(\mathrm{~A})$ & A (Sept) & 2010 & 147 & 6 \\
\hline Leslie & GPS+ACC & B1 & $\mathrm{F}$ & $18(\mathrm{G}), 9(\mathrm{~A})$ & $\mathrm{S}$ (Apr) & 2010 & 151 & 8 \\
\hline Maud & GPS+ACC & L6a & $\mathrm{F}$ & $11(\mathrm{G}), 9(\mathrm{~A})$ & A (Nov) & 2009 & 126 & 1 \\
\hline
\end{tabular}

${ }^{\mathrm{a}}$ Tag, GPS or ACC (accelerometer) or both

${ }^{\mathrm{b}}$ Territory, territory identifier

${ }^{\mathrm{c}} \mathrm{Sex}(\mathrm{M}=$ male, $\mathrm{F}=$ female $)$

${ }^{\mathrm{d}} N_{\text {night }}$, number of nights in original dataset

${ }^{\mathrm{e}}$ Season ( $\mathrm{S}=$ spring: April-May, $\mathrm{A}=$ autumn: August-November)

${ }^{\mathrm{f}}$ Year, year of monitoring

${ }^{\mathrm{g}}$ Npos, number of valid GPS positions per individual for seven nights

${ }^{\mathrm{h}}$ Ncapt, number of times the animals have been captured before
(ODBA, in units of gravity $g$ ) and 'principal activity periods' (in minutes). Mean ODBA at $8 \mathrm{~Hz}$ was calculated by summing up the dynamic acceleration logged in all three axes (Wilson et al. 2006) and averaged over 15 min to investigate movement-based activity levels for each individual. The beavers' principal activity periods were determined visually by identifying movement patterns indicating when the beavers left their lodges (indicated by the first dive in the evening) and returned to the lodges again (the last dive in the morning followed by a grooming session; for information on behavioural identification using accelerometry, see Graf et al. (2015)). The first night was excluded from this analysis since we captured beavers that night and thus did not have a full principal activity period. 
We also standardized the GPS dataset for all individuals to seven nights. For improving spatial accuracy, we cleaned the raw GPS data by removing all fixes with horizontal dilution of precision (HDOP) values $\geq 5$ or with only two dimensions (2D) (Lewis et al. 2007). Further, the GPS fix rate was raised from 15 to $30 \mathrm{~min}$ to increase the amount of consecutive GPS fixes (necessary for calculating distances) and to reduce the number of missing values. The final dataset used for analyses had an overall fix rate performance (potential GPS fixes vs. actual GPS fixes of cleaned dataset) of $75 \%$. Based on the GPS data, we created two movement response variables: 'distance moved' (m) - the distance between two consecutive GPS fixes in 30-min intervals - and 'lodge displacement rate (LDR)' - the distance ( $\mathrm{m}$ ) of each GPS position (taken every $30 \mathrm{~min}$ ) to the individual's main lodge. For calculating displacement rates from lodges, we identified active lodges within each territory by visually screening the GPS positions in ArcMap10 (ESRI, Redlands, CA, USA), in particular the first and last positions for each night (the time of emerging and returning to the lodge). A map containing both active and old lodges which were used by beavers over the years was then used to localize the coordinates for the relevant main lodges.

We created linear mixed-effects (LME) models using the nlme package (Pinheiro et al. 2016) including the timevariable 'minutes after release' as the main predictor for 'mean ODBA', 'distance moved' and 'LDR', and the main predictor 'night' for 'principal activity period' (since we just had one data point per night). In all models, we used the covariates 'season' (spring: April-May, autumn: August-November), 'sex', 'total number of times captured before' (typically between 0 and three times within a year; F. Rosell, unpublished results; total $\tilde{x}=5.0, \mathrm{IQR}=2-7)$ and 'tag load' $(1=$ either GPS or accelerometer, a lighter and smaller tag, $2=$ both GPS and accelerometer, a heavier and larger tag). In addition, we included 'territory size' (calculated as bank length, $\bar{x}=$ $3650.8 \pm 1524.6 \mathrm{~m}$ ) as a covariate in analyses based on GPS data. For the response variables 'mean ODBA', 'distance moved' and 'LDR', we included 'individual' nested within 'year' as random effect. For the response variable 'principal activity period', we only included 'individual' as random effect, due to the smaller sample size. However, mean principal activity periods were similar between years (Kruskal-Wallis test, $\chi^{2}=5.534, d f=2, p=0.063$ ).

The three response variables 'mean ODBA', 'distance moved' and 'LDR' were log-transformed to meet the LME model's assumptions for normally distributed residuals. When necessary, we also accounted for non-independence of errors due to temporal autocorrelation of the response variables by adding a first-order autoregressive term (corAR1) to our models (Pollitt et al. 2012; Zuur et al. 2009). No collinearity between independent variables were detected $(r<0.6$ in all cases) and variance inflation factors (vif) for all models were $<3$ (see Zuur et al. 2010). We used a backward model selection procedure and selected the most parsimonious model based on the Akaike information criterion corrected for small sample sizes $\left(\mathrm{AIC}_{\mathrm{c}}\right)$ and $\mathrm{AIC}_{\mathrm{c}}$ differences $\left(\Delta \mathrm{AIC}_{\mathrm{c}}\right.$ ) (Burnham et al. 2010; Wagenmakers and Farrell 2004). We selected the final models from a subset of top models with strong levels of empirical support $\left(\Delta \mathrm{AIC}_{\mathrm{c}}=0-2\right)$ (Anderson 2008). Model parameters that included zero within their $95 \%$ confidence interval (CI) were considered as uninformative (Arnold 2010). Cohen's $d$ scores (Cohen 1988), $\beta$ estimates and coefficients of determination $\left(R^{2}\right)$ were used as a measure of effect size (Nakagawa and Cuthill 2007). Bootstrapped CIs for taggingrelated informative responses were reported using the bootES package (Kirby and Gerlanc 2013).

\section{Results}

We analysed data from 29 individual dominant beavers (12 females, 17 males), 3 of these beavers were captured a second time (Table 1). As the period of time between subsequent captures was at least 2 years (2, 3 and 5 years) and a different tag type (GPS vs. accelerometer) was deployed on the second capture, we included both datasets in our analysis. The accelerometer dataset consisted of 14 beavers ( 5 females, 9 males) and GPS dataset of 23 beavers (11 females, 12 males); five individuals were represented in both datasets as they were tagged with a combination of GPS unit and accelerometer (Table 1). Accelerometer data was collected in 11 different territories and included in total 7-19 nights; GPS data was collected in 15 different territories and included 7-23 nights per individual (Table 1). We analysed only six nights of acceleration data for one beaver (Chris, Table 1), since the unit ran out of battery. For the same reason, analyses of principal activity period for the last night (night 8; analyses started on night 2) included acceleration data for only 8 out of 14 individuals. For four individuals, we got only one GPS location in the first night (indicating that the beavers went into their lodges) and could thus calculate distances moved only for nights 2-7. We removed one individual (Loran, Table 1) from our LDR analysis since we were unable to identify the main lodge and calculate corresponding displacement rates (he used two lodges at distances that could be covered within the sampling interval of the GPS units). As the first night after release was shorter than the following six nights, we also ran all models without night 1 , but found that the results were unchanged for all response variables. Initially, we also included the predictor 'handling time' in all models; however, since there were several missing values, this lowered sample sizes considerably (GPS data: $n=12$, acceleration data: $n=11$ ). As handling time was uninformative, and in order to maintain the original sample size, we did not include this predictor in the final models. The predictors included in the most parsimonious models for the four response variables are presented in 
Table 2 (for full model selection, see Additional Tables S1-S4 given in Online Resource 1); informative predictors and according model outcomes are shown in Table 3.

\section{Mean ODBA}

The grand median for mean ODBA values for seven nights was $0.15 \mathrm{~g}$ with an IQR of $0.13-0.19 \mathrm{~g}$. Mean ODBA was best explained by the main predictor 'minutes after release' (Table 2), with beavers showing a lower activity level after release (Table 3, Fig. 2). The standardized effect size (Cohen's d) for differences in mean ODBA values in the first and the seventh night was $0.17(\mathrm{LL}=0.04, \mathrm{UL}=0.30)$. This small effect size (Cohen 1988), in combination with the low power of the other model effect statistics $\beta$ and $R^{2}$ (Table 3), suggests only a minimal difference in activity level within the first week after release. Plotting mean ODBA values over time also revealed a periodicity in the activity level, with lower activity levels at the beginning and at the end of the night (Fig. 2).

\section{Principal activity period}

Mean principal activity period in the first week was $10.95 \pm$ $1.19 \mathrm{~h}$. Beavers started their principal activity periods on average at $20: 19 \mathrm{~h} \pm 58 \mathrm{~min}$ in the evening and went back into their lodges in the morning on average at $07: 16 \mathrm{~h} \pm 57 \mathrm{~min}$. The best model included the main predictor 'night' and the covariates 'season', 'tag load', 'number of times captured before' and 'sex' (Table 2). By investigating the CI's for the dependent variables, we found only season to be informative, with beavers being active for shorter periods in spring (Table 3).

\section{Distance moved}

Median distance moved in $30 \mathrm{~min}$ was $158.52 \mathrm{~m}$ for the seven nights with an IQR of 56.63-316.70 m. Distance moved was best explained by territory size (Table 2), with beavers in larger territories covering greater distances (Table 3 ).

\section{Lodge displacement rate (LDR)}

Median LDR for the seven nights was $359.56 \mathrm{~m}$ with an IQR of 179.69-634.36 m. LDR was best explained by season (Table 2); however, CI's for $\beta$ estimates incorporated 0 ( $\beta=$ $0.18, \mathrm{LL}=-0.09, \mathrm{UL}=0.45)$ and we thus considered season as an uninformative variable.

\section{Discussion}

Short-term tagging effects on Eurasian beavers included only changes in their activity level, with beavers having a lower mean ODBA after release. However, the small effect size for mean ODBA calls the practical relevance of this finding into question (Sullivan and Feinn 2012). Four individuals went back into their lodges after release and stayed there until the next day (night 2). This finding indicates that individual beavers may alter their behaviour in response to the tagging event in the capture night. Contrary to our predictions, principal activity periods, distances moved and LDR were not altered by the tagging event. In a study on North American beavers, Smith et al. (2016) found no effects of transmitters (both tailtags and implants) on the animals' short- and long-term survival (monthly and annual over 8 years) when compared to ear-tagged beavers only. While body condition was similar for the two groups, beavers with transmitters had higher winter weight loss, which could have been trigged by tail-tagging and transmitters tearing out of the tail, respectively, since the beaver tail serves as a fat storage depot (Aleksiuk 1970). Nontagging related, but informative effects included longer principal activity periods in autumn and greater distances covered by beavers living in larger territories. The latter result is intuitive and accords with Graf et al. (2016), who showed that beavers exhibit different movement strategies in relation to territory sizes and describe the same relationship for a different subset of beavers from the same study area. In contrast to two studies that found no seasonal differences in principal
Table 2 Most parsimonious models based on Akaike's information criterion corrected for small sample sizes $\left(\mathrm{AIC}_{\mathrm{c}}\right)$ for the four response variables for 29 dominant Eurasian beavers (C. fiber) in Telemark, southeastern Norway (2009-2014)

\begin{tabular}{|c|c|c|c|c|}
\hline Response variable & Most parsimonious model & $\mathrm{AIC}_{\mathrm{c}}{ }^{\mathrm{a}}$ & $w_{i}^{\mathrm{b}}$ & $K^{\mathrm{c}}$ \\
\hline Mean ODBA & MIN & -1039.89 & 0.76 & 6 \\
\hline Principal activity period & $\begin{array}{l}\text { NIGHT + SEASON + TAG_LD + TIMES_CAPT + } \\
\text { SEX }\end{array}$ & 906.04 & 0.96 & 9 \\
\hline Distance moved & TERR_SIZE & 7746.97 & 1 & 4 \\
\hline $\begin{array}{l}\text { Lodge displacement } \\
\text { rate }\end{array}$ & SEASON & 6627.08 & 1 & 6 \\
\hline
\end{tabular}

MIN minutes after release, TAG_LD tag load, TIMES_CAPT times captured before, TERR_SIZE territory size measured as bank length (m)

${ }^{\text {a }}$ Akaike information criterion adjusted for small sample sizes

${ }^{\mathrm{b}}$ Akaike weight

${ }^{\mathrm{c}}$ Number of parameters 
Table 3 Model outcomes for the three response variables with informative predictors for 29 dominant Eurasian beavers (C. fiber) in Telemark, southeastern Norway (2009-2014)

\begin{tabular}{llrrrrr}
\hline Response variable & $\begin{array}{l}\text { Informative model } \\
\text { term }\end{array}$ & $\beta^{\mathrm{a}}$ & $\sigma^{\mathrm{b}}$ & $\mathrm{LL}^{\mathrm{c}}$ & $\mathrm{UL}^{\mathrm{d}}$ & $\mathrm{R}^{2 \mathrm{e}}$ \\
\hline Mean ODBA $^{\mathrm{f}}$ & $\begin{array}{l}\text { Minutes after } \\
\text { release }\end{array}$ & $2.15 \mathrm{e}^{-05}$ & $4.20 \mathrm{e}^{-06}$ & $1.33 \mathrm{e}^{-05}$ & $2.98 \mathrm{e}^{-05}$ & 0.29 \\
$\begin{array}{c}\text { Principal activity } \\
\text { period }\end{array}$ & $\begin{array}{c}\text { Season spring } \\
\text { Distance moved }\end{array}$ & -100.464 & 42.815 & -197.318 & -3.610 & 0.58 \\
\hline
\end{tabular}

${ }^{\text {a }}$ Estimated regression coefficient

${ }^{\mathrm{b}}$ Standard error,

${ }^{\mathrm{c}}$ Lower $95 \%$ confidence levels around the estimated coefficient $(\beta \pm 1.96 \times \sigma)$

${ }^{\mathrm{d}}$ Upper $95 \%$ confidence levels around the estimated coefficient $(\beta \pm 1.96 \times \sigma)$

${ }^{\mathrm{e}}$ Coefficient of determination

${ }^{\mathrm{f}}$ Log-transformed model outcomes activity periods (Sharpe and Rosell 2003; Swinnen et al. 2015), we suggest that longer principal activity periods in autumn could be coupled with winter preparations such as food-caching behaviour (Busher 1996; Hartman and Axelsson 2004) and lodge repair work (Żurowski 1992).

\section{Reduced activity level (mean ODBA)}

We found a time-dependent increase in beaver activity (manifest by mean ODBA) after the tagging event. However, the

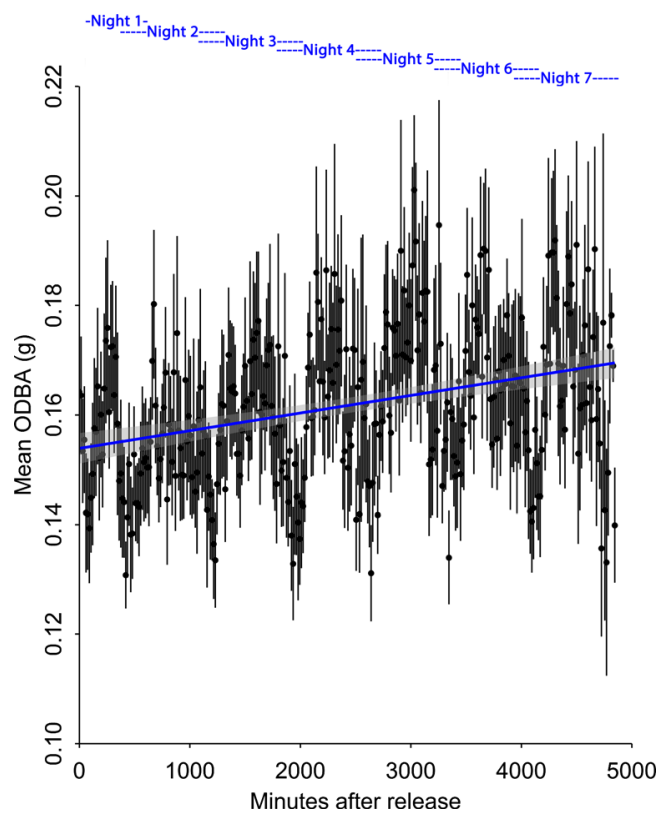

Fig. 2 Linear relationship (regression line and $95 \%$ confidence interval) between mean ODBA and minutes after release for 14 dominant Eurasian beavers (C. fiber) in Telemark, southeastern Norway (2009-2014). The axis on top of the graph shows the different nights after release; overlap results from the different capture times in the first night. Each point represents the overall mean $( \pm \mathrm{SE})$ over individual mean ODBA values measured every $15 \mathrm{~min}$ after the tagging event. Periodic oscillations of ODBA means for each night suggest similar activity patterns of all individuals, with an activity peak in the middle of their active period $(\sim 7 \mathrm{pm}$ to $7 \mathrm{am})$ small effect size $(d=0.17)$ likely equates to a small difference in terms of activity and thus implies only minor biological relevance. Besides these effect size issues, a more vigilant and cautious behaviour after release may be responsible for the observed lower mean ODBA levels. In their study on antipredator behaviour of North American beavers, Basey and Jenkins (1995) showed that the animals would stop periodically between their activities and appeared to look and smell for predators in risky situations (e.g. when presented with predator odour). In agreement with this observation, both Rosell and Czech (2000) and Rosell and Sanda (2006) found a reduced foraging and scent marking behaviour in beavers when confronted with a predator odour.

Periodic oscillations in activity levels of our study animals suggest that beavers seem to follow a similar activity pattern each night, with peaks during the mid-part of the beavers' principal activity periods. Similar oscillations in activity levels were found in all study animals during the seven nights. Higher mean ODBA levels in the middle of the night suggest that this is the peak activity time for beavers. The mean ODBA value for standing (or being inactive) is $0.06 \mathrm{~g}$ ( $\sigma=0.02 \mathrm{~g}$ ) (Graf et al. 2015) and none of our mean ODBA values was below $0.1 \mathrm{~g}$, which suggests that the animals were active during all seven nights after the tagging event.

\section{No short-term effects on principal activity period, distances moved and LDR}

We found no evidence for short-term tagging effects on principal activity periods, distances moved and LDR. This contrasts a study by Ranheim et al. (2004), who implanted radio transmitters in 22 adult beavers from the same study area and found that beavers spent more time inside their lodges within the first few days after release. Similarly, Sharpe and Rosell (2003), who worked with a subset of 12 adult beavers with implanted radio transmitters, report that beavers spent more time inside their lodges in the first two days post-release. 
However, capture effects were not the main focus of these studies and were thus just reported anecdotal. In addition, both Ranheim et al. (2004) and Sharpe and Rosell (2003) used anaesthesia and surgery (in the latter study in 10 out of 12 beavers), which is likely to have a greater impact than our quick, non-invasive tagging-method. An advantage of our net-capture method from the boat (Rosell and Hovde 2001) is that there is only a short time lag between the capture and handling event, which substantially reduces the overall time used for the handling and tagging procedure. Certainly, shortened handling periods appear to help mitigate stress (e.g. Bosson et al. 2012; Ponjoan et al. 2008). Even though some studies claim that using chemical immobilization reduces capture and handling stress (Montané et al. 2002; Read et al. 2000), we argue that not using anaesthesia can be an advantage: Our procedure meant that beavers were released immediately back into their familiar surroundings (including lodges and burrows for refuge) without adverse affects from anaesthesia and/or surgery. Tagged beavers were quite often observed swimming or foraging shortly after release (F. Rosell, personal communication), which confirms our assumption.

\section{Territoriality against all odds}

We found no effect of the tagging procedure on the beavers' spatial movement within their territories and suggest that principal activity periods and movement patterns of territorial animals may be constrained by the need for territorial defence. Kukalová et al. (2013) found that edible dormice (Glis glis) switched their den site after being handled, but returned on average after 4 days. The authors suggest that the level of territoriality may play a role in a species' response to handling and tagging with animals returning to the same place because of a defended resource in the area. Similarly, daily patrolling and scent marking is an important constituent of the beaver's nightly routine (Rosell et al. 1998), particularly for the dominant individuals as they are the main contributors of territory defence (Rosell and Thomsen 2006). In beaver populations at carrying capacity, such as in our study area (Campbell et al. 2005; Steyaert et al. 2015), the risks of intrusion following insufficient territory maintenance might be high (Steyaert et al. 2015). Due to this, there is likely strong selection pressure for beavers to resume their nightly routines even shortly after the tagging event.

\section{The effect of habituation}

The number of times a beaver had been captured before did not affect movement and activity within the first week after tagging. Beavers in our study area are typically captured and handled for the first time when they are still kits and all animals in this study have been captured at least once before. It has been shown that a single exposure to a stressor can induce long-term changes in neuroendocrine and behavioural stress responses (Armario et al. 2008). Lynn et al. (2010) measured plasma corticosterone levels in free-living Eastern bluebirds (Sialia sialis) and found a reduced stress response 7 weeks after a single first exposure to capture and handling. However, most studies on this topic have been conducted in captivity and have measured subsequent stress responses within just a few days or weeks (for review, see Wiedenmayer 2004). Other studies have found no such effects and argue that habituation needs repeated handling at relatively short intervals (several times per week) (Hämäläinen et al. 2014). In addition, the interval between two subsequent captures for individual beavers in this study can range up to several years and it is not clear whether beavers possess a long-term memory that can relate to past events in this order. Consequently, for determining whether habituation in beavers can occur after just a single exposure to a stressor and last over extended time periods, further research on neuroendocrine stress responses is needed.

\section{Drag}

A major issue invoked by researchers working with external tags on aquatic animals is that of drag (e.g. Bannasch et al. 1994; Culik et al. 1994; Jones et al. 2011), which is not expected to change over wearing time since it is a purely physical constraint. The power required to overcome drag $(P)$ is given by $P=0.5 \mathrm{ACd} v^{3} \rho$, where $A$ is the cross-sectional area of the animal, $C d$ is the drag coefficient, $\rho$ is the density of the fluid medium and $v$ is the velocity. Thus, although our attached device would increase the drag by increasing the cross-sectional area marginally, it is the swim speed that is going to be a prime modulator of increased energy expenditure (Vandenabeele et al. 2015). Importantly, work by Vandenabeele et al. (2015) showed that up to speeds of $1.5 \mathrm{~m} / \mathrm{s}$, the energy consumption of a tag-fitted great cormorant Phalacrocorax carbo was unlikely to differ much from the untagged conspecific, but that differences between them accelerated quickly thereafter. Thus, since beavers generally swim between $0.8 \mathrm{~m} / \mathrm{s}$ on the surface (Nolet and Rosell 1994) and $0.6 \mathrm{~m} / \mathrm{s}$ when submerged (Allers and Culik 1997), we would not expect drag-based power to compromise the animals greatly. This does not, however, apply to fast swimming manoeuvres, such as during escape responses (e.g. tail-slap dives; see Hodgdon and Larson 1973; Wilsson 1971), and this warrants further consideration.

\section{Future perspectives}

Ideally, tagging effects should be analysed by combining both behavioural and physiological data (e.g. blood parameters and/or faeces; Bosson et al. 2012; Harcourt et al. 2010; Rehnus et al. 2009; Sheriff et al. 2011). Indeed, capture effects 
might only be physiological (Kock et al. 1987; Meyer et al. 2008) and do not necessarily imply visible behavioural changes. Likely, these effects do not lead to a bias of results in behavioural studies, but do still have implications regarding animal welfare. Moreover, a period of 7 days might be too short to detect alterations in behavioural patterns, and perhaps may not cover the whole habituation period. The technical constraints we experienced in our study, which were mainly related to battery life and the size of the unit, meant we were not able to investigate longer time periods for all individuals. Other studies have described habituation periods to last for 4 days in the common brushtail possum (Trichosurus vulpecula) (Dennis and Shah 2012), 10 days in European roe deer (Capreolus capreolus) (Morellet et al. 2009), or even 2 and up to 4 weeks in white-tailed deer (Odocoileus virginianus) and pygmy rabbits (Brachylagus idahoensis), respectively (Dechen Quinn et al. 2012; Rachlow et al. 2014). However, these differences in habituation periods may be related to the study species' ecology, as well as the different capture and handling procedures and are thus hard to put into perspective here. Another difficulty in investigating tagging effects by using logged data is that 'measurement may affect performance'-i.e. the simple act of having a tag on an animal means there is no control for when it has no tag at all (cf. Wilson et al. 1986). Only long-term studies on lifetime reproductive success or survival and/or control observations of untagged individuals (see Authier et al. 2013) may deliver answers to that indirectly (Bro et al. 1999; Côté et al. 1998). Indeed, the issue of proper control in studies such as these is likely to be perennial.

\section{Conclusion}

In this study, we emphasize the potential of bio-logged data to investigate tagging effects on study animals and highlight awareness of such effects. This is important for animal welfare and for the development of methods that mitigate tagging effects, but also for avoiding biased research results. We found short-term tagging effects only related to activity levels, which were of low practical relevance due to the small effect size. The discovery that there were no changes in principal activity periods, distances moved and LDR indicates that beavers were active and did not change space use within the territory following tagging. Based on these results, we suggest excluding data from the capture night from analyses. Ultimately, combined bio-logging with physiological data, as well as longterm data on life history parameters such as fitness and survival, should be examined for getting deeper insights into an animal's response to tagging events.

Acknowledgments Open access funding provided by University of Natural Resources and Life Sciences Vienna (BOKU). The authors thank Christian A. Robstad and Manuel E. Echeverria for trapping, and Andreas
Zedrosser, Friedrich Leisch and Shane Frank for statistical advice. This study was funded by the University College of Southeast Norway, the Norwegian Environment Agency, the county councils of Telemark, Vestfold and Oslo municipality (Urban Environment Agency).

Open Access This article is distributed under the terms of the Creative Commons Attribution 4.0 International License (http:// creativecommons.org/licenses/by/4.0/), which permits unrestricted use, distribution, and reproduction in any medium, provided you give appropriate credit to the original author(s) and the source, provide a link to the Creative Commons license, and indicate if changes were made.

\section{References}

Aleksiuk M (1970) The function of the tail as a fat storage depot in the beaver (Castor canadensis). J Mammal 51:145-148. doi:10.2307 $/ 1378541$

Allers D, Culik BM (1997) Energy requirements of beavers (Castor canadensis) swimming underwater. Physiol Zool 70:456-463. doi:10.1086/515852

Anderson DR (2008) Model based inference in the life sciences: a primer on evidence. Springer, New York

Armario A, Escorihuela RM, Nadal R (2008) Long-term neuroendocrine and behavioural effects of a single exposure to stress in adult animals. Neurosci Biobehav Rev 32:1121-1135. doi:10.1016/j. neubiorev.2008.04.003

Arnold TW (2010) Uninformative parameters and model selection using Akaike's information criterion. J Wildl Manag 74:1175-1178. doi:10.1111/j.1937-2817.2010.tb01236.x

Authier M, Péron C, Mante A, Vidal P, Grémillet D (2013) Designing observational biologging studies to assess the causal effect of instrumentation. Methods Ecol Evol 4:802-810. doi:10.1111/2041-210X.12075

Bannasch R, Wilson RP, Culik B (1994) Hydrodynamic aspects of design and attachment of a back-mounted device in penguins. J Exp Biol 194:83-96

Barron DG, Brawn JD, Weatherhead PJ (2010) Meta-analysis of transmitter effects on avian behaviour and ecology. Methods Ecol Evol 1: 180-187. doi:10.1111/j.2041-210X.2010.00013.x

Basey JM, Jenkins SH (1995) Influences of predation risk and energy maximization on food selection by beavers (Castor canadensis). Can J Zool 73:2197-2208

Bergman BG, Bump JK (2015) Experimental evidence that the ecosystem effects of aquatic herbivory by moose and beaver may be contingent on water body type. Freshw Biol 60:1635-1646

Blanchet M-A, Lydersen C, Biuw M, de Bruyn PJN, Hofmeyr G, Krafft BA, Kovacs KM (2014) Instrumentation and handling effects on Antarctic fur seals (Arctocephalus gazella). Polar Res. doi:10.3402 /polar.v33.21630

Bosson C, Islam Z, Boonstra R (2012) The impact of live trapping and trap model on the stress profiles of North American red squirrels. J Zool 288:159-169

Boyd IL, Kato A, Ropert-Coudert Y (2004) Bio-logging science: sensing beyond the boundaries. Mem Natl Inst Polar Res 58:1-14

Bro E, Clobert J, Reitz F (1999) Effects of radiotransmittes on survival and reproductive success of gray partridge. J Wildl Manag 63:1044 1051. doi: $10.2307 / 3802820$

Broell F, Taylor AD, Litvak MK, Bezanson A, Taggart CT (2016) Posttagging behaviour and habitat use in shortnose sturgeon measured with high-frequency accelerometer and PSATs. Animal Biotelemetry 4:1-13. doi:10.1186/s40317-016-0103-x 
Burnham KP, Anderson DR, Huyvaert KP (2010) AIC model selection and multimodel inference in behavioral ecology: some background, observations, and comparisons. Behav Ecol Sociobiol 65:23-35. doi:10.1007/s00265-010-1029-6

Busher PE (1996) Food caching behavior of beavers (Castor canadensis): selection and use of woody species. Am Midl Nat 135:343-348. doi: $10.2307 / 2426717$

Butler PJ, Green JA, Boyd IL, Speakman JR (2004) Measuring metabolic rate in the field: the pros and cons of the doubly labelled water and heart rate methods. Funct Ecol 18:168-183

Cagnacci F, Boitani L, Powell R, Boyce M (2010) Animal ecology meets GPS-based radiotelemetry: a perfect storm of opportunities and challenges. Phil Transac Royal Soc B-Biol Sci 365:2157-2162

Calenge C (2006) The package adehabitat for the R software: a tool for the analysis of space and habitat use by animals. Ecol Modell 197:516-519

Campbell RD, Rosell F, Nolet BA, Dijkstra VA (2005) Territory and group sizes in Eurasian beavers (Castor fiber): echoes of settlement and reproduction? Behav Ecol Sociobiol 58:597-607

Campbell RD, Nouvellet P, Newman C, MacDonald DW, Rosell F (2012) The influence of mean climate trends and climate variance on beaver survival and recruitment dynamics. Glob Chang Biol 18:2730 2742. doi:10.1111/j.1365-2486.2012.02739.x

Campbell RD, Newman C, Macdonald DW, Rosell F (2013) Proximate weather patterns and spring green-up phenology effect Eurasian beaver (Castor fiber) body mass and reproductive success: the implications of climate change and topography. Glob Chang Biol 19: 1311-1324. doi:10.1111/gcb.12114

Casas F, Benítez-López A, García JT, Martín CA, Viñuela J, Mougeot F (2015) Assessing the short-term effects of capture, handling and tagging of sandgrouse. Ibis 157:115-124

Cattet M, Macbeth BJ, Janz DM, Zedrosser A, Swenson JE, Dumond M, Stenhouse GB (2014) Quantifying long-term stress in brown bears with the hair cortisol concentration: a biomarker that may be confounded by rapid changes in response to capture and handling. Cons. Physiol. 2. doi:10.1093/conphys/cou026

Cohen J (1988) Statistical power analysis for the behavioral sciences, 2nd edn. Erlbaum, New Jersey

Cooke S, Woodley C, Brad Eppard M, Brown R, Nielsen J (2011) Advancing the surgical implantation of electronic tags in fish: a gap analysis and research agenda based on a review of trends in intracoelomic tagging effects studies. Rev Fish Biol Fish 21:127151. doi:10.1007/s11160-010-9193-3

Côté SD, Festa-Bianchet M, Fournier F (1998) Life-history effects of chemical immobilization and radiocollars on mountain goats. $\mathrm{J}$ Wildl Manag 62:745-752

Cross HB, Zedrosser A, Nevin O, Rosell F (2014) Sex discrimination via anal gland secretion in a territorial monogamous mammal. Ethology 120:1044-1052

Culik B, Bannasch R, Wilson R (1994) External devices on penguins: how important is shape? Mar Biol 118:353-357

Dechen Quinn AC, Williams DM, Porter WF (2012) Postcapture movement rates can inform data-censoring protocols for GPS-collared animals. J Mammal 93:456-463. doi:10.1644/10-MAMM-A-422.1

Dennis TE, Shah SF (2012) Assessing acute effects of trapping, handling, and tagging on the behavior of wildlife using GPS telemetry: a case study of the common brushtail possum. J Appl Anim Welf Sci 15: 189-207. doi:10.1080/10888705.2012.683755

Evans AL, Singh NJ, Friebe A, Arnemo JM, Laske TG, Fröbert O, Swenson JE, Blanc S (2016) Drivers of hibernation in the brown bear. Front Zool 13:1-14. doi:10.1186/s12983-016-0140-6

Fletcher QE, Boonstra R (2006) Impact of live trapping on the stress response of the meadow vole (Microtus pennsylvanicus). J Zool 270:473-478. doi:10.1111/j.1469-7998.2006.00153.x

Friebe A, Evans AL, Arnemo JM, Blanc S, Brunberg S, Fleissner G, Swenson JE, Zedrosser A (2014) Factors affecting date of implantation, parturition, and den entry estimated from activity and body temperature in free-ranging brown bears. PLoS One 9, e101410. doi:10.1371/journal.pone.0101410

Gendron D, Serrano IM, de la Cruz AU, Calambokidis J, Mate B (2014) Long-term individual sighting history database: an effective tool to monitor satellite tag effects on cetaceans. Endanger Species Res 26:235-241

Gleiss AC, Norman B, Wilson RP (2011) Moved by that sinking feeling: variable diving geometry underlies movement strategies in whale sharks. Funct Ecol 25:595-607. doi:10.1111/j.13652435.2010.01801.x

Godfrey JD, Bryant DM (2003) Effects of radio transmitters: review of recent radio-tracking studies. In: Williams, M (Comp.) 2003: Conservation applications of measuring energy expenditure of New Zealand birds: assessing habitat quality and costs of carrying radio transmitters. Sci Conserv 214:83-95

Golabek KA, Jordan NR, Clutton-Brock TH (2008) Radiocollars do not affect the survival or foraging behaviour of wild meerkats. J Zool 274:248-253. doi:10.1111/j.1469-7998.2007.00377.x

Graf PM, Wilson RP, Qasem L, Hackländer K, Rosell F (2015) The use of acceleration to code for animal behaviours; a case study in freeranging Eurasian beavers Castor fiber. PLoS One 10, e0136751. doi:10.1371/journal.pone.0136751

Graf PM, Mayer M, Zedrosser A, Hackländer K, Rosell F (2016) Territory size and age explain varying movement patterns in the Eurasian beaver. Mamm Biol 81:587-594. doi:10.1016/j. mambio.2016.07.046

Haarberg O, Rosell F (2006) Selective foraging on woody plant species by the Eurasian beaver (Castor fiber) in Telemark, Norway. J Zool 270:201-208. doi:10.1111/j.1469-7998.2006.00142.x

Hämäläinen A, Heistermann M, Fenosoa ZSE, Kraus C (2014) Evaluating capture stress in wild gray mouse lemurs via repeated fecal sampling: method validation and the influence of prior experience and handling protocols on stress responses. Gen Comp Endocrinol 195:68-79

Harcourt RG, Turner E, Hall A, Waas JR, Hindell M (2010) Effects of capture stress on free-ranging, reproductively active male Weddell seals. J Comp Physiol A 196:147-154. doi:10.1007 /s00359-009-0501-0

Hartman G, Axelsson A (2004) Effect of watercourse characteristics on food-caching behaviour by European beaver, Castor fiber. Anim Behav 67:643-646

Herr J, Rosell F (2004) Use of space and movement patterns in monogamous adult Eurasian beavers (Castor fiber). J Zool 262:257-264. doi:10.1017/s0952836903004606

Hodgdon HE, Larson JS (1973) Some sexual differences in behaviour within a colony of marked beavers (Castor canadensis). Anim Behav 21:147-152

Höfle U, Millán J, Gortázar C, Buenestado FJ, Marco I, Villafuerte R (2004) Self-injury and capture myopathy in net-captured juvenile red-legged partridge with necklace radiotags. Wildl Soc Bull 32:344-350. doi:10.2193/0091-7648(2004)32[344 :SACMIN]2.0.CO;2

Jenkins SH (1980) A size-distance relation in food selection by beavers. Ecology 61:740-746. doi:10.2307/1936743

Jones TT et al (2011) Determining transmitter drag and best-practice attachment procedures for sea turtle biotelemetry. NOAA Tech Memo NMFS-SWFSC 480:58

Kays R, Crofoot MC, Jetz W, Wikelski M (2015) Terrestrial animal tracking as an eye on life and planet. Science 348. doi:10.1126/ science.aaa2478

Kirby KN, Gerlanc D (2013) BootES: an R package for bootstrap confidence intervals on effect sizes. Behav Res Methods 45:905-927. doi:10.3758/s13428-013-0330-5

Kissling DW, Pattemore DE, Hagen M (2014) Challenges and prospects in the telemetry of insects. Biol Rev 89:511-530 
Kock M, Clark R, Franti C (1987) Effects of capture on biological parameters in free-ranging bighorn sheep (Ovis canadensis): evaluation of normal, stressed and mortality outcomes and documentation of postcapture survival. J Wildl Dis 23:652-662

Kukalová M, Gazárková A, Adamík P (2013) Should I stay or should I go? The influence of handling by researchers on den use in an arboreal nocturnal rodent. Ethology 119:848-859. doi:10.1111 /eth.12126

Lapointe MA, Bauer CM, Ebensperger LA, Reed JM, Romero LM (2015) Livetrapping is not biased by the endocrine stress response: a preliminary study in the degu (Octodon degus). J. Mammal. doi:10.1093/jmammal/gyv081

Lewis JS, Rachlow JL, Garton EO, Vierling LA (2007) Effects of habitat on GPS collar performance: using data screening to reduce location error. J Appl Ecol 44(3):663-671

Lynn SE, Prince LE, Phillips MM (2010) A single exposure to an acute stressor has lasting consequences for the hypothalamo-pituitaryadrenal response to stress in free-living birds. Gen Comp Endocrinol 165:337-344

McMahon CR, Field IC, Bradshaw CJA, White GC, Hindell MA (2008) Tracking and data-logging devices attached to elephant seals do not affect individual mass gain or survival. J Exp Mar Bio Ecol 360:7177. doi:10.1016/j.jembe.2008.03.012

McMahon CR, Collier N, Northfield JK, Glen F (2011) Taking the time to assess the effects of remote sensing and tracking devices on animals. Anim Welf 20:515-521

Meyer LC, Fick L, Matthee A, Mitchell D, Fuller A (2008) Hyperthermia in captured impala (Aepyceros melampus): a fright not flight response. J Wildl Dis 44:404-416

Montané J, Marco I, Manteca X, López J, Lavín S (2002) Delayed acute capture myopathy in three roe deer. J Vet Med A Physiol Pathol Clin Med 49:93-98

Morellet N, Verheyden H, Angibault JM, Cargnelutti B, Lourtet B, Hewison MAJ (2009) The effect of capture on ranging behaviour and activity of the European roe deer Capreolus capreolus. Wildl Biol 15:278-287. doi:10.2981/08-084

Nakagawa S, Cuthill IC (2007) Effect size, confidence interval and statistical significance: a practical guide for biologists. Biol Rev 82:591-605

Nathan R, Spiegel O, Fortmann-Roe S, Harel R, Wikelski M, Getz WM (2012) Using tri-axial acceleration data to identify behavioral modes of free-ranging animals: general concepts and tools illustrated for griffon vultures. J Exp Biol 215:986-996. doi:10.1242/jeb.058602

Nolet BA, Rosell F (1994) Territoriality and time budgets in beavers during sequential settlement. Can J Zool 72:1227-1237. doi:10.1139/z94-164

Novak M (1987) Beaver. In: Novak M, Baker JA, Obbard ME, Malloch B (eds) Wild furbearer management and conservation in North America. Ontario Ministry of Natural Resources, Ontario, pp 283312

Olstad O (1937) Beverens (Castor fiber) utbredelse i Norge. Statens viltundersøkelser. Offprint of Nytt magasin for naturvidenskapene 77:217-273

O'Mara MT, Wikelski M, Dechmann DKN (2014) 50 years of bat tracking: device attachment and future directions. Methods Ecol Evol 5: 311-319. doi:10.1111/2041-210X.12172

Pinheiro J, Bates D, Debroy S, Sarkar D, Development Core Team R (2016) Nlme: linear and nonlinear mixed effects models. R package version 3:1-127

Pollitt LC, Reece SE, Mideo N, Nussey DH, Colegrave N (2012) The problem of auto-correlation in parasitology. PLoS Pathog. 8. doi: 10.1371/journal.ppat.1002590

Ponjoan A, Bota G, García De La Morena EL, Morales MB, Wolff A, Marco I, Mañosa S (2008) Adverse effects of capture and handling little bustard. J Wildl Manag 72:315-319. doi:10.2193/2006-443
R Development Core Team (2013). R: a language and environment for statistical computing. R foundation for statistical computing, Vienna, Austria. URL http://www.R-project.org/

Rachlow JL, Peter RM, Shipley LA, Johnson TR (2014) Sub-lethal effects of capture and collaring on wildlife: experimental and field evidence. Wildl. Soc. Bull.:n/a-n/a. doi:10.1002/wsb.444

Ranheim B, Rosell F, Haga HA, Arnemo JM (2004) Field anaesthetic and surgical techniques for implantation of intraperitoneal radio transmitters in Eurasian beavers Castor fiber. Wildl Biol 10:11-15

Read M, Caulkett N, McCallister M (2000) Evaluation of zuclopenthixol acetate to decrease handling stress in wapiti. J Wildl Dis 36:450-459

Rehnus M, Hackländer K, Palme R (2009) A non-invasive method for measuring glucocorticoid metabolites (GCM) in Mountain hares (Lepus timidus). Europ J Wildl Res 55:615-620. doi:10.1007 /s10344-009-0297-9

Rhodes JR, McAlpine CA, Lunney D, Possingham HP (2005) A spatially explicit habitat selection model incorporating home range behaviour. Ecology 86:1199-1205. doi:10.1890/04-0912

Ropert-Coudert Y, Wilson R (2005) Trends and perspectives in animalattached remote sensing. Front Ecol Environ 3:437-444. doi: $10.2307 / 3868660$

Ropert-Coudert Y, Knott N, Chiaradia A, Kato A (2007) How do different data logger sizes and attachment positions affect the diving behaviour of little penguins? Deep Sea Res Part 2 Top Stud Oceanogr 54: 415-423. doi:10.1016/j.dsr2.2006.11.018

Ropert-Coudert Y, Kato A, Poulin N, Grémillet D (2009) Leg-attached data loggers do not modify the diving performances of a footpropelled seabird. J Zool 279:294-297. doi:10.1111/j.14697998.2009.00619.x

Rosell F, Czech A (2000) Responses of foraging Eurasian beavers Castor fiber to predator odours. Wildl Biol 6:13-21

Rosell F, Hovde B (2001) Methods of aquatic and terrestrial netting to capture Eurasian beavers. Wildl. Soc. Bull.:269-274

Rosell F, Sanda JI (2006) Potential risks of olfactory signaling: the effect of predators on scent marking by beavers. Behav Ecol 17:897-904. doi:10.1093/beheco/arl022

Rosell F, Thomsen LR (2006) Sexual dimorphism in territorial scent marking by adult Eurasian beavers (Castor fiber). J Chem Ecol 32:1301-1315

Rosell F, Bergan F, Parker H (1998) Scent-marking in the Eurasian beaver (Castor fiber) as a means of territory defense. J Chem Ecol 24:207-219

Rutz C, Hays GC (2009) New frontiers in biologging science. Biol Lett 5: 289-292. doi:10.1098/rsbl.2009.0089

Ryan JA, Ulrich JM (2014) xts: eXtensible Time Series. R package version $0.9-7$

Saraux C et al (2011) Reliability of flipper-banded penguins as indicators of climate change. Nature 469:203-206. doi:10.1038/nature09630

Schofield G, Bishop CM, MacLean G, Brown P, Baker M, Katselidis KA, Dimopoulos P, Pantis JD, Hays GC (2007) Novel GPS tracking of sea turtles as a tool for conservation management. J Exp Mar Bio Ecol 347:58-68. doi:10.1016/j.jembe.2007.03.009

Schulte BA (1998) Scent marking and responses to male castor fluid by beavers. J Mammal 79:191-203

Sharpe F, Rosell F (2003) Time budgets and sex differences in the Eurasian beaver. Anim Behav 66:1059-1067. doi:10.1006 /anbe.2003.2274

Shepard E et al (2008) Identification of animal movement patterns using tri-axial accelerometry. Endanger Species Res 10:47-60. doi: $10.3354 /$ esr00084

Sheriff MJ, Dantzer B, Delehanty B, Palme R, Boonstra R (2011) Measuring stress in wildlife: techniques for quantifying glucocorticoids. Oecologia 166:869-887. doi:10.1007/s00442-011-1943-y

Shillinger GL, Bailey H, Bograd SJ, Hazen EL, Hamann M, Gaspar P, Godley BJ, Wilson RP, Spotila JR (2012) Tagging through the stages: technical and ecological challenges in observing life histories 
through biologging. Mar Ecol Prog Ser 457:165-170. doi:10.3354 /meps09816

Smith JB, Windels SK, Wolf T, Klaver RW, Belant JL (2016) Do transmitters affect survival and body condition of American beavers Castor canadensis? Wildl Biol 22:117-123. doi:10.2981/wlb.00160

Spiegel O, Harel R, Centeno-Cuadros A, Hatzofe O, Getz WM, Nathan R (2015) Moving beyond curve fitting: using complementary data to assess alternative explanations for long movements of three vulture species. Am Nat 185:E44-E54. doi:10.1086/679314

St. Aubin DJ, Forney KA, Chivers SJ, Scott MD, Danil K, Romano TA, Wells RS, Gulland FMD (2013) Hematological, serum, and plasma chemical constituents in pantropical spotted dolphins (Stenella attenuata) following chase, encirclement, and tagging. Mar Mamm Sci 29:14-35. doi:10.1111/j.1748-7692.2011.00536.x

Steyaert SMJG, Swenson JE, Zedrosser A (2014) Litter loss triggers estrus in a nonsocial seasonal breeder. Ecol Evol 4(3):300-310

Steyaert SM, Zedrosser A, Rosell F (2015) Socio-ecological features other than sex affect habitat selection in the socially obligate monogamous Eurasian beaver. Oecologia 179:1023-1032. doi:10.1007 /s00442-015-3388-1

Sullivan GM, Feinn R (2012) Using effect size - or why the p value is not enough. J Grad Med Educ 4:279-282. doi:10.4300/JGME-D-12-00156.1

Sun L, Müller-Schwarze D (1999) Chemical signals in the beaver. In: Johnston RE, Müller-Schwarze D, Sorensen PW (eds) Advances in chemical signals in vertebrates. Springer US, Boston, pp 281288. doi:10.1007/978-1-4615-4733-4 23

Swinnen KRR, Hughes NK, Leirs H (2015) Beaver (Castor fiber) activity patterns in a predator-free landscape. What is keeping them in the dark? Mamm Biol 80:477-483. doi:10.1016/j.mambio.2015.07.006

Thorrold SR, Afonso P, Fontes J, Braun CD, Santos RS, Skomal GB, Berumen ML (2014) Extreme diving behaviour in devil rays links surface waters and the deep ocean. Nat Commun 5. doi:10.1038/ ncomms 5274

Tinnesand HV, Jojola S, Zedrosser A, Rosell F (2013) The smell of desperadoes? Beavers distinguish between dominant and subordinate intruders. Behav Ecol Sociobiol 67:895-904. doi:10.1007 /s00265-013-1512-y

Vandenabeele S, Shepard E, Grémillet D, Butler P, Martin G, Wilson R (2015) Are bio-telemetric devices a drag? Effects of external tags on the diving behaviour of great cormorants. MEPS 519:239-249

Wagenmakers E-J, Farrell S (2004) AIC model selection using Akaike weights. Psychon Bull Rev 11:192-196
Weimerskirch H (2007) Are seabirds foraging for unpredictable resources? Deep Sea Res Part 2 Top Stud Oceanogr 54:211-223. doi:10.1016/j.dsr2.2006.11.013

White CR, Cassey P, Schimpf NG, Halsey LG, Green JA, Portugal SJ (2013) Implantation reduces the negative effects of bio-logging devices on birds. J Exp Biol 216:537-542. doi:10.1242/jeb.076554

Wiedenmayer CP (2004) Adaptations or pathologies? Long-term changes in brain and behavior after a single exposure to severe threat. Neurosci Biobehav Rev 28:1-12

Williams TM, Wolfe L, Davis T, Kendall T, Richter B, Wang Y, Bryce C, Elkaim GH, Wilmers CC (2014) Instantaneous energetics of puma kills reveal advantage of felid sneak attacks. Science 346:81-85. doi:10.1126/science. 1254885

Wilson RP (2011) Animal behaviour: the price tag. Nature 469:164-165. doi: $10.1038 / 469164 \mathrm{a}$

Wilson RP, McMahon CR (2006) Measuring devices on wild animals: what constitutes acceptable practice? Front Ecol Environ 4:147-154

Wilson RP, Grant WS, Duffy DC (1986) Recording devices on freeranging marine animals: does measurement affect foraging performance? Ecology 67:1091-1093

Wilson RP, White CR, Quintana F, Halsey LG, Liebsch N, Martin GR, Butler PJ (2006) Moving towards acceleration for estimates of activity-specific metabolic rate in free-living animals: the case of the cormorant. J Anim Ecol 75:1081-1090. doi:10.1111/j.13652656.2006.01127.x

Wilson ADM, Wikelski M, Wilson RP, Cooke SJ (2015) Utility of biological sensor tags in animal conservation. Conserv Biol 29:10651075. doi:10.1111/cobi.12486

Wilsson L (1971) Observations and experiments on the ethology of the European beaver (Castor fiber L.). Viltrevy 8:115-266

Zimmermann B, Wabakken P, Sand H, Pedersen HC, Liberg O (2007) Wolf movement patterns: a key to estimation of kill rate? J Wildl Manag 71:1177-1182. doi:10.2193/2006-306

Żurowski W (1992) Building activity of beavers. Acta Theriol (Warsz) 37:403-411

Zuur A, Ieno EN, Walker N, Saveljev AA, Smith GM (2009) Mixed effects models and extensions in ecology with R. Springer, New York. doi:10.1007/978-0-387-87458-6

Zuur AF, Ieno EN, Elphick CS (2010) A protocol for data exploration to avoid common statistical problems. Methods Ecol Evol 1:3-14. doi:10.1111/j.2041-210X.2009.00001.x 